\title{
LA POLÍTICA EXTERIOR DEL GOBIERNO MEXICANO EN EL PACÍFICO ASIÁTICO (2012-2018)
}

\author{
THE EXTERNAL POLICY OF THE MEXICAN \\ GOVERNMENT IN THE ASIA-PACIFIC REGION (2012-2108)
}

\author{
LA POLITIQUE ÉTRANGÈRE DU GOUVERNEMENT \\ MEXICAIN VIS-À-VIS DE L'ASIE-PACIFIQUE (2012-2018)
}

Carlos Uscanga

Universidad Nacional Autónoma de México, UNAM auscanga@politicas.unam.mx

Resumen: En las últimas décadas, el sur, el este y el sudeste de Asia han tenido un extraordinario crecimiento y una gran capacidad de innovación tecnológica, por lo que los gobiernos mexicanos la han considerado como una región potencial para la diversificación de sus relaciones económicas. Empero, en una valoración comprehensiva, México se ha quedado corto en la capitalización de mayores oportunidades de negocios y en profundizar sus nexos diplomáticos. Con esos retos dio inicio el sexenio del presidente Enrique Peña Nieto (2012-2018), que fue eficiente en "administrar" sus relaciones internacionales, sin aportar mayor valor agregado en la consecución de sus objetivos iniciales de política exterior, en un contexto de volatilidad de los factores internos y externos.

Palabras clave: Pacífico asiático; México; política exterior; diversificación; administración.

AвSTRACT: In recent decades, the south, east, and southeast of Asia have seen extraordinary growth and a great capacity for technological innovation, a reason why Mexican governments have seem it as a potential region for the diversification of their economic relations. However, taking an overall perspective, Mexico has failed to capitalize on greater business opportunities or on deepening its diplomatic ties. These challenges marked the beginning of the presidency of President Enrique Peña Nieto (2012-2018), who was efficient in "managing" international relations, without providing added value in achiev- 
ing his original foreign policy objectives, in a context of internal and external volatility.

Keywords: Asia Pacific; Mexico; foreign policy; diversification; administration.

\section{Traducción de Gonzalo Celorio Morayta}

RÉsumé: Au cours des dernières décennies, l'Asie du Sud, de l'Est et du SudEst ont bénéficié d'une croissance extraordinaire et d'une grande capacité d'innovation technique, dont les possibilités ont été remarquées par plusieurs gouvernements mexicains souhaitant diversifier les rapports économiques de leur pays. Néanmoins, une analyse fouillée met en évidence que le Mexique n'a pas fait assez pour profiter des opportunités d'affaires ni pour approfondir les liens diplomatiques. L'ambition d'y arriver était présente au démarrage de la période d'Enrique Peña Nieto, un président qui a été efficace pour administrer les relations internationales, quoique sans obtenir des profits supplémentaires dans la poursuite des buts de la politique étrangère qu'il a établis au début de son mandat, lesquels se sont heurtés à une atmosphère d'éléments internes et internationaux fort variables.

Mots clefs: Asie-Pacifique; Mexique; politique étrangère; diversification; administration.

Traducción de BERNARDo MabiRE

Fecha de recepción: diciembre de 2018

Fecha de aceptación: febrero de 2019 
$\mathrm{C}$ OMO se vaticinaba a lo largo del siglo xx, la región Asia Pacífico ha experimentado importantes transformaciones en el terreno económico, político y social que han permitido la emergencia de una arquitectura regional marcada, sin lugar a duda, por el ascenso de China como una potencia global, el posicionamiento de las economías emergentes asiáticas en las redes de producción y con una mayor visibilidad en la política internacional, además de ser actores relevantes en los foros mundiales. Quizá un aspecto desestimado en esos análisis fue que Japón no logró o no pudo ejercer mayor influencia y liderazgo en la región. Sin embargo, India ha tenido en Asia del sur, el mayor crecimiento del producto interno bruto (PIB) entre las economías que integran el G20. Frente a esas dinámicas transformaciones, México ha expresado constantemente, en el discurso oficial, la necesidad de vincularse más con el Pacífico asiático. En este contexto de grandes transformaciones económicas y políticas dio inicio la administración de Enrique Peña Nieto, el $1^{\circ}$ de diciembre de 2012.

El presente artículo se propone esbozar las principales iniciativas internacionales realizadas por el gobierno mexicano en la subregión del Pacífico asiático durante el sexenio, en tres planos. ${ }^{1}$ En primer lugar, enumerar algunas medidas desplegadas en el terreno político-diplomático en el ámbito bilateral, identificando a sus socios prioritarios y relevantes; en segundo, identificar algunas actividades durante la participación de México en los principales foros regionales, para después hacer un balance global del sexenio 2012-2018. En ese sentido, se parte del supuesto de que el diseño y las estrategias de la política exterior de México en el Pacífico asiático mantuvieron espacios de continuidad en la gestión de sus relaciones internacionales, a pesar de los cambios institucionales dentro de la Secretaría de Relaciones Exteriores (SRE), la

${ }^{1}$ El balance de las principales acciones de política exterior en el Pacífico asiático durante 2012-2018 no incluye China ni las negociaciones del TPP у СPTPP. 
volatilidad política de la agenda interna y el factor disruptivo de la llegada de Donald Trump a la presidencia de Estados Unidos (EEUU), observándose en la agenda global para el este, sur y sudeste de Asia, un atisbo de profundidad con la propuesta del esquema de diálogo regional miкTa (México, Indonesia, Corea del Sur, Turquía y Australia) en 2013.

En ese contexto, un aspecto que es menester tomar en consideración es la cada vez más profunda interacción entre los factores internos y externos que permean los diferentes planos en el proceso de toma de decisiones de la política exterior, permitiendo superposiciones ${ }^{2}$ que inciden en su operatividad y en los niveles de eficacia de las estrategias y acciones emprendidas en el ámbito internacional. En el caso mexicano, la merma en sus niveles de gobernabilidad de los últimos sexenios, los escándalos mediáticos por corrupción y el avance del crimen organizado, ${ }^{3}$ eclipsaron los esfuerzos para revertir la tradicional política exterior reactiva, encapsulando y aislando los intentos de proactividad.

En el caso del Pacífico asiático, está claro que México ha fallado, tanto en forjar una visión de mediano y largo plazo, como en ser un actor visible en el ámbito económico y político regional, al carecer de una lectura integral y adecuada de las transformaciones vertiginosas que ha tenido esa parte del mundo durante las últimas décadas. No obstante, el gobierno mexicano ha mostrado capacidad de respuesta (con diferentes grados de eficiencia) a los temas del día a día de la agenda regional; lo anterior refleja la solidez de la estructura institucional que permite la continuidad de sus tareas de gestión administrativa, independientemente de asumir un perfil pasivo o más dinámico en el marco internacional.

2 R. Domínguez, "Teorías contemporáneas de política exterior", en M. C. Dávila y R. Cuéllar (coords.), La política exterior de México y sus nuevos desafios, México, unam/Plaza y Valdés, 2008, pp. 26-27.

${ }^{3}$ G. González y O. Pellicer, Los retos internacionales de México. Urgencia de una mirada nueva, México, Editorial Siglo xxi, 2011, p. 12. 


\section{Planeación y eXPectativas}

El inicio de la administración de Enrique Peña Nieto ofrecía un panorama alentador para el impulso de su agenda internacional. Por un lado, el Pacto por México abría el camino para avanzar en las postergadas reformas estructurales que podrían impulsar el crecimiento económico del país, así como posicionarlo en un lugar atractivo para la expansión de los negocios internacionales. ${ }^{4}$ Por el otro, el nuevo gobierno afirmaba tener un nuevo enfoque para contrarrestar la inseguridad y el avance del crimen organizado que habían proliferado a pesar de la declaración de la "guerra contra el narcotráfico" durante el periodo precedente de Felipe Calderón Hinojosa. ${ }^{5}$

La relación con Estados Unidos durante la administración de Barack Obama se mantenía estable, por lo que le permitía desplegar una estrategia de política exterior más efectiva, en tanto que había mayores márgenes de gobernabilidad interna y un alto índice de aprobación por el retorno del Partido Revolucionario Institucional (PRI) al poder. Esto abría el camino para la proyección de México como un país con responsabilidades globales, desplegando sus potencialidades máximas, tal como lo refería el Plan Nacional de Desarrollo (PND) 2012-2018. 6

En ese contexto tan prometedor, la nueva administración arrancaba con cuatro aspectos que debía atender en el Pacífico asiático. En primer lugar, resarcir las relaciones con Beijing después de los desencuentros originados por los gobiernos del Partido de Acción Nacional (PAN); en segundo,

${ }^{4}$ J. de Alba, "Enrique Peña Nieto y el primer año de gobierno", Revista de Relaciones Internacionales de la UNAM, núm. 119 (mayo-agosto 2014), pp. 139-140.

${ }^{5}$ R. Velázquez, "El proyecto de política exterior de Felipe Calderón: ¿golpe de timón?, Revista de Relaciones Internacionales de la UNAM, núm. 108 (septiembre-diciembre de 2010), pp. 122-123.

${ }^{6}$ Gobierno de la República, Plan Nacional de Desarrollo 2013-2018, México, 2013, https://www.gob.mx/presidencia/acciones-y-programas/ plan-nacional-de-desarrollo-2013-2018-78557 
continuar los trabajos en las rondas de negociación del TPP (Acuerdo Estratégico de Asociación Transpacífico) después de la incorporación de México, junto con Canadá, a ese mecanismo de comercio en octubre del 2012. ${ }^{7}$ En tercero, responder las recurrentes solicitudes de Corea del Sur para reanudar las negociaciones para la firma de un Tratado de Libre Comercio suspendidas desde $2008 .^{8}$ En cuarto lugar, profundizar los nexos con en el Acuerdo para el Fortalecimiento de la Asociación Económica (AFAE), que entró en vigor en 2005, y en la que se avizoraba un fuerte impulso por la anunciada llegada de la inversión extranjera directa (IED) japonesa concentrada en el sector automotriz.

Ante ese panorama, en el PND se identificaba como directiva consolidar los nexos con la región de Asia Pacífico, ampliando la diversificación económica y maximizando los vínculos comerciales y diplomáticos con sus "socios relevantes". En el Plan Sectorial de Relaciones Exteriores 2013-2018 no se explicita el significado de "socios relevantes", pero se refiere al hecho de que había que profundizar los nexos con los siguientes países: Australia, India, Indonesia, Singapur y Corea del Sur, así como con Malasia, Tailandia y Vietnam para incrementar el comercio, los flujos de turismo e inversión. ${ }^{9}$ En el informe de labores de la SRE del 2013, se destaca que el gobierno mexicano tiene como meta consolidar la presencia del país en esa región, debido a su gran potencial, constante crecimiento y desarrollo, entre los cuales China, Corea del Sur, Japón y la India son países prioritarios, ${ }^{10}$ clasi-

${ }^{7}$ F. L. de Rosenzweig Mendialdua, "México y su ingreso en el Acuerdo de Asociación Transpacífico”, Revista de Derecho Económico Internacional, vol. 3, núm. 1, pp. 89-94.

${ }^{8}$ C. Uscanga, "La diplomacia de «último recurso» en la negociación del Tratado de Libre Comercio entre México y Corea del Sur, Revista Asia y América, vol. 11, núm. 1 (2011), pp. 165-181.

${ }^{9}$ Programa Sectorial de Relaciones Exteriores 2013-2018, Diario Oficial de la Federación, 13 de diciembre de 2013, p. 19.

${ }^{10}$ Secretaría de Relaciones Exteriores,SRE, Primer Informe de Labores de la SRE 2012-2013, México, sRE, 2013, p. 68, https://sre.gob.mx/organo- 
ficación que se utilizará para el presente análisis. Con esas naciones, México tiene un diálogo político y diplomático permanente y fuertes vínculos en el ámbito de la cooperación, así como relaciones económicas consolidadas.

Los "socios relevantes" pueden dividirse en dos grupos; por un lado estarían los miembros del MiкTA: particularmente Indonesia y Australia, referido como un grupo que incluye "economías significativas" y "democracias consolidadas", que busca fortalecer la consulta y coordinación de temas; y por el otro, los países que participan con México en el TPP y después en el CPTPP (Tratado Integral y Progresista de Asociación Transpacífico), donde se incluye a Nueva Zelanda, Singapur, Malasia, Vietnam y Brunéi Darussalam. El tercer gran grupo estaría integrado por el resto de los países de la región del sudeste y sur de Asia, donde se atiende la cotidiana agenda bilateral diplomática y de cooperación, sin mayor profundidad en las acciones políticas y económicas.

La estrategia 1.6 del Programa Sectorial de Relaciones Exteriores 2013-2018 se refería al objetivo de potenciar la presencia de México mediante la ampliación de las relaciones bilaterales, la transformación por medio del fortalecimiento del contacto político, la presencia diplomática y la apertura de oportunidades en materia comercial, inversión y cooperación, todo lo anterior acompañado de la promoción de México en la región. Asimismo, se apunta a la necesidad de continuar y ampliar su participación en los foros regionales como el mecanismo de Cooperación Económica Asia-Pacífico (APEC, por sus siglas en inglés), el Foro de Cooperación América Latina-Asia del Este, (FocalaE) y el Consejo de Cooperación Económica del Pacífico (PECC, por sus siglas en inglés), y mantener una línea de comunicación con

interno-de-control-en-la-sre / 75-transparencia-y-acceso-a-la-informacionpublica-gubernamental/transparencia-y-acceso-a-la-informacion-publi ca-gubernamental1548-primer-informe-de-labores (consulta del 24 de junio de 2018). 
la Asociación de Naciones del Sudeste de Asia (asean, por sus siglas en inglés).

Asimismo, es de hacer notar que el tema de la cooperación lo refiere tanto en el ámbito bilateral, con los "socios prioritarios y relevantes", pero también con el "resto de los países" en diferentes áreas, incluyendo la innovación tecnológica, ${ }^{11}$ y en general se menciona el hecho de que la cooperación para el desarrollo es otro aspecto que debe atenderse, junto a otros temas globales como el combate al cambio climático y la migración.

\section{A LA ACCIÓN}

La operación de la política exterior de México en el Pacífico asiático tuvo que enfrentar las vicisitudes de la agenda política interna y los efectos colaterales de la campaña electoral en EEUU con el discurso antimigrante y contra el TLCAN y el TPP. Lo anterior generó tres relevos en la conducción de la SRE, lo cual implicó un desgaste de la energía institucional ante los frecuentes cambios de los equipos de trabajo y la focalización con Estados Unidos por el triunfo de Donald Trump.

$\mathrm{Si}$ bien las anteriores fueron variables relevantes que repercutieron en la respuesta de México frente a los cambios en el contexto internacional, en el caso de los nexos con el este, sudeste y sur de Asia se logró mantener diferentes canales y medios para atender la agenda de México con la región del Pacífico asiático. Es decir, puede apreciarse la presencia de diferentes y múltiples niveles para el desahogo de los asuntos "normales" de la agenda, pero también para la consulta de asuntos de perfil extraordinario. En todo ese universo es posible identificar los siguientes tipos de reuniones efectuados a lo largo del sexenio 2012-2018:

11 Secretaría de Relaciones Exteriores, SRE, Programa sectorial, $o p$. cit., p. 28. 
a) Encuentros para preparación y las visitas de Estado o de trabajo del ejecutivo o de sus contrapartes.

b) Seguimiento de acuerdos o negociación de mecanismos, consultas y cooperación, como se observó con MIKTA, además de pronunciamientos como grupo ante hechos y sucesos de impacto regional y global (las pruebas nucleares y el lanzamiento de misiles de Corea del Norte).

c) Visitas específicas para atender aspectos de la agenda bilateral, en lo particular temas pendientes, en los que también se hacían consultas con el encuentro de altos funcionarios o de los responsables del gobierno, un ejemplo en ese sentido fue la insistencia de Corea del Sur para concluir el TLC pendiente con México.

d) Reuniones de prenegociación o búsqueda de posicionamientos compartidos en temas regionales, pero también de atención de aspectos bilaterales entre miembros, como sería el caso de México con sus socios del TTP para la conclusión y firma del documento, pero después para formular un esquema alterno ante la salida de Washington y lograr el consenso de los once países restantes para proponer el CPTPP.

e) Encuentros constantes para el diagnóstico y propuestas de nuevas iniciativas de la agenda "cotidiana" bilateral.

Está claro que la cancillería mexicana buscó aprovechar todos los canales institucionales, incluyendo los de comités o comisiones binacionales, las reuniones de los foros oficiales multilaterales (ONU, G20), informales (Boao) y en particular los regionales. En ese sentido cabe destacar las asociaciones con cuatro países, China, (Asociación Estratégica Integral, 2013), Corea del Sur (Asociación Estratégica para la Prosperidad Mutua, 2005), Japón (Asociación Estratégica Global para el Siglo XXI, 2010) e India (asociación privilegiada, 2007) que dieron continuidad a los temas de la agenda bilateral. En el caso del último país, se abordó la cuestión de elevar la asociación para conferirle carácter estratégico, durante el encuen- 
tro del presidente Peña Nieto con el primer ministro Narendra Modi en el verano de 2016.

Es relevante mencionar también las consultas realizadas con Indonesia en octubre de 2013, adonde Peña Nieto hizo una visita oficial y sostuvo una reunión con el presidente $\mathrm{Su}-$ silo Bambang Yudhoyono, con quien coincidió en trabajar conjuntamente para elevar el nivel de la relación bilateral a fin de alcanzar una asociación integral. En tanto que con los restantes países del sudeste asiático y del Pacífico sur se expresó el interés por aumentar los intercambios políticos, económicos y de cooperación. Asimismo, la participación en foros de cooperación transpacífica, que se identificó como un objetivo de su política exterior; además, a lo largo del sexenio de Peña Nieto pudo observarse la presencia y atención a los temas regionales.

En ese universo de actividades más relevantes del ejecutivo mexicano relacionadas con el Pacífico asiático, indudablemente pueden destacarse las visitas de Estado y las denominadas agendas de trabajo o no oficiales, la recepción de jefes de Estado o de gobierno, y los encuentros con sus pares en foros regionales y multilaterales. En ese sentido, se observó una actividad fluida y constante que cumplía las obligaciones protocolarias y se hacían consultas directas con sus contrapartes en temas bilaterales y de interés regional. En la toma de posesión de Enrique Peña Nieto, el $1^{\circ}$ de diciembre de 2012, diferentes mandatarios y sus representantes estuvieron presentes en la ceremonia de apertura de su gobierno. Entre éstos destaca el encuentro en el castillo de Chapultepec con el primer ministro Kim Hwang-sik, en representación del presidente de Corea del Sur, Lee Myungbak, así como la entrevista con el senador Satsuki Eda, quien asistió en carácter de enviado especial del gobierno de Japón. ${ }^{12}$

12 "Concluye reunión de Enrique Peña con dignatarios", La Razón, $1^{\circ}$ de diciembre de 2012, https:/ / www.razon.com.mx/concluye-reunionde-enrique-pena-con-dignatarios / (consulta del 24 de junio del 2018). 
Después de su intervención en el Foro de Boao para Asia (el "Davos" de China, ciudad ubicada en la región de Hainan) en abril del 2013, Peña Nieto efectuó una visita oficial a Japón para fortalecer los vínculos bilaterales, en la cual tuvo un encuentro con el emperador Akihito y con el primer ministro Shinzō Abe, así como con los presidentes de la cámara alta y baja de la Dieta japonesa y con los directivos de la Keidanren (Federación de Negocios de Japón). ${ }^{13}$

$\mathrm{Su}$ estancia en las dos naciones más importantes del este asiático correspondía a la necesidad de mostrar la buena voluntad de México en resarcir los nexos con China (la cual se vería posteriormente comprometida de nuevo con la cancelación del proyecto del tren rápido México-Querétaro), e interesándose en un acercamiento con aquel país; por otro lado, había que refrendar la cercanía con Japón en el contexto de la ampliación de inversiones japonesas en el sector automotriz mexicano.

El presidente asistió a cinco de las seis cumbres de líderes en el marco del APEC (no participó en la realizada en Papúa Nueva Guinea en 2018), aprovechando ese espacio para mantener reuniones y consultas con los máximos representantes de esas economías, pero también para atender actividades de protocolo. Cabe destacar la visita de Estado en noviembre de 2015 a Filipinas, primera de un mandatario mexicano a ese país en más de cincuenta años. ${ }^{14}$ En esta reunión con el presidente Benigno S. Aquino III se evaluó el estado de los nexos económicos y se suscribieron tres instrumentos de cooperación, con el objetivo de evitar la doble imposición sobre la renta y prevenir la evasión fiscal, incrementar los niveles de coo-

${ }^{13}$ Secretaría de Relaciones Exteriores, SRE, Primer Informe de Labores de la SRE 2012-2013, op. cit., p. 69.

14 "Peña Nieto llega a Filipinas; participará en la APEC", El Financiero, México, 17 de noviembre de 2015, http://www.elfinanciero.com.mx/ mundo/pena-nieto-llega-a-filipinas-participara-en-la-apec (consulta del 24 de junio de 2018). 
peración turística y combatir el tráfico ilícito de estupefacientes. ${ }^{15}$

Por mencionar sólo dos casos de visitas de mandatarios asiáticos a México, citamos la de la presidenta de Corea del Sur, Park Geun-hye, a principios de abril de 2016. De acuerdo con el cuarto informe de labores de la SRE, en este encuentro "se firmaron acuerdos de cooperación en materia de comercio, finanzas, recursos hídricos e infraestructura de transporte y se suscribieron catorce acuerdos adicionales. Los mandatarios acordaron continuar promoviendo un ambiente de negocios atractivo para el establecimiento de nuevas empresas coreanas". ${ }^{16}$ Del mismo modo, se discutió el apoyo de México para la posible incorporación sudcoreana al TPP y se abordó el tema del inconcluso TLC bilateral, mientras Peña Nieto se comprometía a valorar las causas de su suspensión técnica.

Asimismo, en la ya mencionada visita del primer ministro de la India, Narendra Modi, en junio de 2016, se acordó elevar el nivel de sus relaciones con una asociación estratégica que reflejara la convergencia en temas políticos, económicos y estratégicos entre ambos países, ampliando el crecimiento de los intercambios comerciales e inversiones recíprocas; así como el incremento de la cooperación en materia tecnológica y ciencia espacial. ${ }^{17}$

Un ejemplo interesante de agendas paralelas del ejecutivo mexicano en la asistencia con organizaciones internacionales fue el encuentro que sostuvo con la consejera de Estado de Myanmar, Aung San Suu Kyi, el primero de alto nivel que se da en cuatro décadas de relaciones diplomáticas entre las dos naciones, en el marco del $71^{\circ}$ periodo de sesiones de la Asamblea General de la Organización de las Naciones Unidas (ONU) en Nueva York. En ese encuentro, ambos manda-

15 Secretaría de Relaciones Exteriores, SRE, Cuarto Informe de Labores de la SRE 2015-2016, op. cit., p. 89.

${ }^{16}$ Loc. cit.

${ }^{17}$ Loc. cit. 
tarios abordaron las respectivas experiencias de sus países en temas de migración. Del mismo modo, Aung San expresó su interés por continuar el diálogo en esa materia y promover mayores intercambios culturales bilaterales. ${ }^{18}$

En suma, las actividades del ejecutivo en reuniones con sus contrapartes en visitas de trabajo y de Estado, así como en el marco de foros regionales o multilaterales fueron constantes y en ellas también se efectuaron consultas de temas bilaterales y de interés global, como el impacto de las políticas de Donald Trump en la economía mundial.

\section{Socios ESTRATÉgicos}

Los vínculos con Japón fueron fluidos al estar sustentados en una relación política y diplomática sólida. Pueden destacarse cuatro momentos: el primero en celebraciones, como la de los 400 años de la llegada de la misión encabezada por Hasekura Tsunenaga Rokuemon a la Nueva España en 1614, en la que se contó con la visita del príncipe y la princesa Akishino de Japón a inicios de octubre de $2014 .{ }^{19}$

De igual manera, en el marco de los 130 años del establecimiento de las relaciones diplomáticas entre México y Japón en 1888, se celebraron diferentes encuentros, entre los que sobresale el del canciller Luis Videgaray y su homólogo japonés, Tarō Konō, donde destacaron la importancia del AFAE como instrumento que ha profundizado las relaciones económicas y en el que el funcionario mexicano reiteró el com-

18 Secretaría de Relaciones Exteriores, SRE, Quinto Informe de Labores de la S.R.E 2016-2017, México, 2017, p. 94, https://sre.gob.mx/sre-docs/ infolab/3erinfolab_a.pdf (consulta del 24 de junio de 2018).

19 Presidencia de la República, "El Presidente Enrique Peña Nieto recibió a los Príncipes Akishino de Japón”, México, 2014, https:// www.gob.mx/presidencia/prensa/el-presidente-enrique-pena-nietorecibio-a-los-principes-akishino-de-japon (consulta del 24 de junio de 2018). 
promiso de su gobierno en proteger las inversiones japonesas frente a la renegociación del TLCAN. ${ }^{20}$

El segundo momento se ubica en reuniones preparatorias y visitas oficiales, como la del secretario José Antonio Meade con su contraparte japonesa, el ministro de Asuntos Exteriores, Fumio Kishida, para organizar la visita oficial del primer ministro de Japón, Shinzō Abe, que tuvo lugar en la Ciudad de México entre el 25 y el 26 de julio de $2014 .^{21}$ En tercero, los encuentros frecuentes para realizar consultas bilaterales sobre el avance y los problemas de la negociación del TTP y, posteriormente, del CPTTP. Por ejemplo, José Antonio Meade sostuvo una entrevista con el viceministro parlamentario superior de la oficina del gabinete de Japón, Yasutoshi Nishimura, en enero de 2015, en la toma de posesión del presidente de Bolivia, Evo Morales, donde ambos funcionarios se refirieron a los avances del TTP .

El cuarto, como resultado de la campaña electoral de Donald Trump y de su posición negativa para continuar el TLCAN, así como del anuncio del retiro de Estados Unidos del TTP después de su toma de posesión, y de la renegociación del instrumento comercial con Estados Unidos y Canadá, se generaron reuniones periódicas de altos funcionarios, lo cual obedecía a las necesidades de dar respuesta a Tokio ante el escenario de incertidumbre.

En ese contexto, en mayo de 2017, el subsecretario de Relaciones Exteriores, Carlos de Icaza, realizó una visita de trabajo a Tokio donde se reunió con altos funcionarios del gobierno japonés y representantes del sector privado y copresidió la VII Reunión del Mecanismo de Consultas Políticas

${ }^{20}$ Secretaría de Relaciones Exteriores, SRE, "El Canciller Videgaray se reúne con el Ministro de Asuntos Exteriores de Japón”, 24 de mayo de 2018, https://www.gob.mx/sre/prensa/el-canciller-videgaray-se-reune-con-el-ministro-de-asuntos-exteriores-de-japon (consulta del 23 de junio de 2018).

${ }^{21}$ Secretaría de Relaciones Exteriores, SRE, Segundo Informe de Labores de la SRE. 2013-2014, México, 2014, p. 80, https://sre.gob.mx/images/sto ries/informe/2doinforme.pdf (consulta del 24 junio de 2018). 
con el viceministro de Asuntos Exteriores, Keiichi Katakami. ${ }^{22}$ Los funcionarios mexicanos se concentraron en informar a los empresarios japoneses que México seguiría trabajando en la protección de las empresas de ese país, aquí instaladas.

En ese mismo sentido, en el verano de 2017, Luis Videgaray Caso, como secretario de la SRE, hizo una visita de trabajo a Tokio y sostuvo un encuentro con Fumio Kishida, ministro de Relaciones Exteriores de Japón, para revisar el estado de los temas principales de la agenda bilateral. ${ }^{23}$ En ese contexto, se organizó un encuentro privado entre Peña Nieto y Shinzō Abe durante el foro de APEC, en Vietnam, en 2017; uno de los aspectos abordados fue el diagnóstico de la política comercial impulsada por el gobierno de Trump. En ese sentido, el mandatario japonés refirió que ambos países comparten "los valores básicos como democracia y libre comercio entre nosotros y tomar la iniciativa a tratar los temas del тPP entre nosotros". ${ }^{24}$ Por su parte, el ejecutivo mexicano agradeció el apoyo japonés en las labores de rescate durante los sismos ocurridos el 7 y 19 de septiembre de 2017.

Asimismo, las reuniones para el seguimiento del proceso de ratificación del CPTPP fueron frecuentes. Ildefonso Guajardo, secretario de Economía, realizó varias visitas a Japón y sostuvo reuniones con funcionarios de ese país. En el verano de 2018 informó a los miembros del Keidanren sobre los compromisos en materia comercial que la política comercial de México ha asumido durante la renegociación del TLCAN y se entrevistó con el canciller japonés Taro Kono, con quien acordó respaldar la rápida implementación del TPP-11, ya

${ }^{22}$ Secretaría de Relaciones Exteriores, SRE, Quinto Informe de Labores de la SRE 2016-2017, op. cit., p. 99.

${ }^{23}$ Ibid, pp. 94-95.

${ }^{24}$ C. Lara, "México y Japón deben ampliar más su relación comercial: Peña Nieto”, El Sol de México, 10 de noviembre de 2017, https:/ /www. elsoldemexico.com.mx/mexico/politica/mexico-y-japon-deben-am pliar-mas-su-relacion-comercial-pena-nieto-310946.html (consulta del 21 junio del 2018). 
que para ambos países era un tema de alta prioridad en sus estrategias comerciales. En ese sentido, Guajardo declaró que el gobierno mexicano haría todo lo posible para que en las rondas de negociaciones con Estados Unidos y Canadá no se afectaran el flujo o la presencia de las inversiones japonesas en México. ${ }^{25} \mathrm{Al}$ final de cuentas, el gobierno mexicano aceptó elevar la regla de origen del 62.5 al $75 \%$ en la concertación del usmca (United States, Mexico and Canada) en octubre del 2018, lo cual generó un importante impacto en la estructura de negocios de las corporaciones japonesas y en particular en el sector automotriz.

Con la India se dio seguimiento a los mecanismos bilaterales y reuniones de altos funcionarios. Se destacan las iniciativas emprendidas en el 65 aniversario de las relaciones diplomáticas entre México y el país asiático en 2015, en las que se enfatizaba la necesidad de incrementar el comercio, las inversiones y estrechar los lazos de cooperación, tal como la ministra de Estado de Comercio e Industria, Daggubati Purandeswari lo expresó frente al secretario José Antonio Meade en su reunión en abril de 2013. ${ }^{26}$

Los mecanismos de diálogo binacional fueron un espacio para evaluar los nexos bilaterales. En marzo de 2014 se llevó a cabo la III reunión del mecanismo de consultas políticas México-India, encabezada por Carlos de Icaza y por el secretario para el Hemisferio Occidental del Ministerio de Asuntos Exteriores de India, Dinkar Khullar. ${ }^{27}$ En octubre del mismo año, el secretario José Antonio Meade hizo una visita de trabajo a Nueva Delhi, con el fin de presidir, junto con su homóloga india, Sushma Swaraj, los trabajos de la VI Reu-

25 Secretaría de Economía, "El Secretario de Economía realiza gira de trabajo a Japón", 10 de junio de 2018, https://www.gob.mx/se/prensa/el-secretario-de-economia-realiza-gira-de-trabajo-a-japon?idiom=es (consulta del 23 de junio del 2018).

${ }^{26}$ Secretaría de Relaciones Exteriores, SRE, Primer Informe de Labores de la SRE 2012-2013, op. cit., p. 73.

27 Secretaría de Relaciones Exteriores, SRE, Segundo Informe de Labores de la SRE 2013-2014, op. cit., p. 84. 
nión de la Comisión Binacional México-India. ${ }^{28}$ En esos mecanismos se abordaron temas como proyectos de cooperación y cultura, turismo, medicina tradicional, agricultura, asuntos consulares, multilaterales y económicos, tal como se observaron también en la VII Reunión de la Comisión Binacional México-India realizada en junio de 2017 en la Ciudad de México. ${ }^{29}$

En los encuentros de alto nivel se destaca el que tuvo Peña Nieto con el primer ministro de India, Narendra Modi, en el marco de su participación en el $70^{\circ}$ periodo de sesiones de la Asamblea General de las Naciones Unidas, en Nueva York, el 28 de septiembre de 2015, en el que se dialogó sobre las oportunidades de intercambio en el ámbito de la tecnología del espacio y sobre otros temas multilaterales de interés común. ${ }^{30}$ Igualmente, el primer ministro destacó su interés en participar en la exploración del petróleo en México, ${ }^{31}$ esto en el marco de las reformas estructurales en ese sector, y un año después de la visita oficial del primer ministro Modi a México, en julio de 2017, en la Cumbre de Líderes del G20 en Hamburgo, se volvió a poner énfasis en "el interés de fortalecer el diálogo político, los flujos económicos y la cooperación bilateral, y subrayaron la importancia de seguir avanzando hacia la meta de alcanzar una Asociación Estratégica”. ${ }^{32}$ En lo general, puede observarse que durante el sexenio de Peña Nieto, con la India, como socio prioritario, se logró tener un

${ }^{28}$ Secretaría de Relaciones Exteriores, SRE, Tercer Informe de Labores de la SRE 2014-2015, op. cit., p. 87.

${ }^{29}$ Secretaría de Relaciones Exteriores, SRE, Quinto Informe de Labores de la SRE 2016-2017, op. cit., p. 100.

${ }^{30}$ Presidencia de la República, "El Presidente Enrique Peña Nieto se reunió con el Primer Ministro de la República de la India, Narendra Modi”, México, 2015, https://www.gob.mx/presidencia/prensa/el-presidente-enrique-pena-nieto-se-reunio-con-el-primer-ministro-de-la-republica-de-la-india-narendra-modi (consulta del 24 de junio del 2018).

${ }^{31}$ Secretaría de Relaciones Exteriores, SRE, Cuarto Informe de Labores de la SRE 2015-2016, op. cit., p. 90.

${ }^{32}$ Secretaría de Relaciones Exteriores, SRE, Quinto Informe de Labores de la SRE 2016-2017, op. cit., p. 93. 
diálogo constante no sólo en los instrumentos de consulta binacionales, sino también en las reuniones de alto nivel.

La relación con Corea del Sur, como socio prioritario y miembro de mikTA, estuvo marcada por las solicitudes de Seúl para reactivar las negociaciones del TLC, mismas que ya se habían elevado al máximo nivel con el encuentro de Peña Nieto y la presidenta Park en los primeros años de su administración. En la reunión del FocALAE, celebrada en Bali, Indonesia, en junio de 2013, el ministro de Asuntos Exteriores, Yun Byung-se, expresó su deseo para impulsar la firma de un tratado de libre comercio, ${ }^{33}$ petición que fue expresada en marzo de 2016 cuando el subsecretario Carlos de Icaza recibió la visita del viceministro para Asuntos Económicos del Ministerio de Relaciones Exteriores, Lee Tae-ho, en la que también se abordaron temas sobre la situación de seguridad en la península coreana, los avances en el espacio MIKTA y la promoción de las inversiones coreanas en México. ${ }^{34}$

En efecto, el tema de las inversiones de Corea del Sur en México también es un tópico recurrente en los encuentros entre funcionarios. Sin embargo, es interesante lo expresado por el subsecretario Carlos de Icaza ante el viceministro Ahn Ching-ghee, afirmando que el gobierno mexicano apreciaba la existencia de las cuantiosas inversiones coreanas, pero el funcionario mexicano refería que la renegociación del TLCAN era un elemento de alta prioridad para el Estado mexicano, por lo que infería que no sería posible, al menos en el corto plazo, atender la petición reiterada de Seúl de la firma de un instrumento para el fomento del libre comercio entre los dos países. ${ }^{35}$

En suma, México mantuvo abiertos, de manera constante, los canales para la atención de los asuntos bilaterales con

${ }^{33}$ Secretaría de Relaciones Exteriores, SRE, Primer Informe de Labores de la SRE 2012-2013, op. cit., p. 71-72.

${ }^{34}$ Secretaría de Relaciones Exteriores, SRE, Cuarto Informe de Labores de la SRE 2015-2016, op. cit., p. 92.

35 Secretaría de Relaciones Exteriores, SRE, Quinto Informe de Labores de la SRE 2016-2017, op. cit., p. 98. 
sus socios prioritarios a través de consultas bilaterales y en las agendas paralelas dentro de los foros regionales y multilaterales. Una constante en el discurso fue la idea de profundizar sus nexos económicos y de colaboración mutua para atender asuntos políticos en el plano regional y global, así como de fortalecer sus lazos de cooperación.

\section{Socios RELEVANTES}

MIKTA, sin lugar a dudas, representó un esfuerzo por parte de México para establecer un mecanismo de consulta con sus socios relevantes, lo cual tuvo continuidad a lo largo del sexenio. Asimismo, ese mecanismo, creado en 2013, obligaba a ejercer acciones más puntuales con los países integrantes, profundizando sus vínculos políticos y de cooperación.

Lo anterior se comprobó con la reunión de Peña Nieto en el foro de Boao con la primera ministra de Australia, Julia Gillard, en la que dialogaron sobre el TPP y el compromiso de ambos países para seguir impulsando el libre comercio, ${ }^{36}$ y en la participación de Peña Nieto en la cumbre de líderes del G20, en Brisbane, en noviembre de 2014, donde se reunió con el entonces nuevo primer ministro de Australia, Tony Abbott, y se celebró también la cuarta reunión de cancilleres MIKTA, en la cual se "intercambiaron puntos de vista sobre el panorama actual de la economía global y establecieron objetivos concretos para estrechar sus vínculos bilaterales y fortalecer su cooperación”. ${ }^{37}$

Además, los contactos a nivel ministerial se intensificaron. José Antonio Meade se reunió en mayo de 2013 con el ministro de Relaciones Exteriores de Indonesia, Marty Natalegawa, durante la visita que este funcionario hizo a México.

36 Secretaría de Relaciones Exteriores, SRE, Primer Informe de Labores de la SRE 2012-2013, op. cit., p. 70.

${ }^{37}$ Secretaría de Relaciones Exteriores, SRE, Tercer Informe de Labores de la SRE 2014-2015, op. cit., p. 89. 
En este acercamiento "coincidieron en la importancia de propiciar encuentros en el marco de los foros regionales para dar un nuevo impulso a la relación". ${ }^{38} \mathrm{Al}$ respecto, Meade resaltó la relevancia de ambos países en el ámbito multilateral, por lo que estuvieron de acuerdo en explorar la posibilidad de pasar a otro nivel de la relación bilateral. ${ }^{39}$

En la primera reunión de altos funcionarios de MIKTA, celebrada en febrero de 2015 en Seúl, se compartieron puntos de vista acerca de temas como promoción comercial, foro empresarial MiкTA, estadías de jóvenes diplomáticos, programa de intercambio entre funcionarios diplomáticos, programa de intercambio estudiantil, reuniones parlamentarias MIKTA, mecanismos de consultas políticas, intercambios culturales, red de académicos, ${ }^{40}$ entre otros, y en la décimo primera reunión de ministros de Relaciones Exteriores celebrada en diciembre de 2017 se destacó la evaluación de programas de capacitación para jóvenes diplomáticos, seminarios sobre desarrollo e innovación, propiedad intelectual y pequeñas y medianas empresas. ${ }^{41}$

Como lo apunta la SRe, con la participación de México en MIKTA se permitió fortalecer contactos con socios no tradicionales ubicados en entornos "geopolíticos diversos", que profundizaron la cooperación y la construcción de un frente común para la atención a los temas globales. ${ }^{42}$

${ }^{38}$ Secretaría de Relaciones Exteriores, SRE, Primer Informe de Labores de la SRE 2012-2013, op. cit., p. 71.

39 Secretaría de Relaciones Exteriores, SRE, Tercer Informe de Labores de la SRE 2014-2015, op. cit., p. 89.

40 Ibid, p. 87.

41 Secretaría de Relaciones Exteriores, sRe, "Se celebró en Estambul la $11^{\text {a }}$ Reunión de Ministros de Relaciones Exteriores de MiкTA”, comunicado núm. 169, 13 de diciembre de 2017, https:/ / www.gob.mx/sre/pren $\mathrm{sa} /$ se-celebro-en-estambul-la-11-reunion-de-ministros-de-relaciones-exte riores-de-mikta (consulta del 24 de junio del 2018).

${ }^{42}$ Loc. cit. 
Foros REGIONALES Y MECANISMOS DE CONSULTA

La participación de México en los principales foros regionales como FOCALAE, PECG y APEC fue congruente con lo dispuesto en las metas de política exterior durante la administración de Peña Nieto, sirviendo como plataforma para la atención de la agenda propia del organismo y de aspectos bilaterales. Los temas de esos mecanismos están alineados con la necesidad de fortalecer la cooperación, así como el impulso de aspectos para mejorar la conectividad intrarregional y fomentar un crecimiento inclusivo, entre otros. Puede citarse, como un valor agregado en la agenda de México con el sudeste de Asia, el primer encuentro ministerial entre la Alianza del Pacífico y ASEAn, en septiembre de 2014, donde se discutieron los trabajos de ambos procesos de integración, así como en posibles espacios de colaboración. En la segunda reunión ministerial, se acordó fortalecer la cooperación birregional de manera gradual e iniciar el trabajo en los sectores de educación, turismo e innovación, con miras a generar, paulatinamente, un mayor acercamiento entre ambos mecanismos de integración. ${ }^{43}$ Los participantes "destacaron el potencial en materia comercial de ambos mecanismos, así como su interés en estrechar vínculos y apoyar a las PYMES para fomentar el emprendimiento e incrementar el comercio mutuo". ${ }^{44}$

Sin lugar a duda, sumado a los anteriores foros regionales, APEC es el más importante por las reuniones ministeriales y la cumbre anual de líderes. Enrique Peña Nieto, durante la reunión en Beijing en noviembre de 2014, hizo declaraciones en torno "al rechazo al proteccionismo y abogó por la apertura de mercados en la región Asia Pacífico. Asimismo, apoyó las medidas para impulsar el desarrollo de las PYMES

43 "Ruiz Massieu participa en reunión de Alianza del Pacífico y ANSEA", (en línea), Excélsior, México, 28 de septiembre de 2015, http:/ /www. excelsior.com.mx/nacional/2015/09/28/1048151 (consulta del 24 de junio del 2018).

${ }^{44}$ Idem. 
en la región”. ${ }^{45}$ En Manila, en 2015, participó en la reunión de líderes del TPP, así como en el primer diálogo informal entre los líderes de APEC y de la Alianza del Pacífico. ${ }^{46}$

En la cumbre de 2016, Peña Nieto y los otros líderes de APEC abordaron temas como "los desafíos del libre comercio y las inversiones en el contexto global actual, la seguridad alimentaria, la adaptación al cambio climático y el acceso al agua, así como la integración de Asia-Pacífico mediante una conectividad real y funcional". ${ }^{47}$ En la última reunión a la que asistió en el 2017 en Vietnam, se reunió con los líderes de las economías que lo integran, y celebró un encuentro con el primer ministro de Japón, Shinzō Abe, en el cual ratificaron el interés por expandir en la comunidad internacional valores como la democracia y el libre comercio, así como temas bilaterales en la renegociación del TLCAN. ${ }^{48}$

Como se apuntó, sin lugar a dudas el espacio de la negociación del TPP y del CPTPP sirvió de marco para el acercamiento con los socios relevantes. José Antonio Meade recibió la visita de su homólogo de Singapur, K. Shanmugam, en mayo de 2014, y conversaron sobre el potencial de la relación bilateral y su aprovechamiento, así como del fortalecimiento de los lazos políticos, económico-comerciales, de cooperación educativa-cultural y científica-técnica. ${ }^{49}$ Además, es de destacar algunos encuentros realizados durante el

45 Secretaría de Relaciones Exteriores, SRE, Tercer Informe de Labores de la SRE, 2014-2015, op. cit., p. 83.

46 Secretaría de Relaciones Exteriores, SRE, Cuarto Informe de Labores de la SRE, 2015-2016, op. cit., p. 90.

47 Secretaría de Relaciones Exteriores, SRE, Quinto Informe de Labores de la SRE, 2016-2017, op. cit., p. 94.

48 Secretaría de Economía, "México participará en la XXV Reunión de Líderes Económicos del Foro de Cooperación Económicas Asia-Pacífico (APEC)", Gobierno de la República, México, 10 de noviembre de 2017, https://www.gob.mx/se/articulos/mexico-participara-en-la-xxv-reunionde-lideres-economicos-del-foro-de-cooperacion-economica-asia-pacificoapec-133708?idiom=es (consulta del 25 de junio del 2018).

${ }^{49}$ Secretaría de Relaciones Exteriores, SRE, Tercer Informe de Labores de la SRE, 2014-2015, op. cit., p. 160. 
sexenio, como la III Reunión del Mecanismo de Consultas Políticas México-Singapur, que tuvo lugar en la Ciudad de México en enero de 2015, en la que se abordó el tema de la conmemoración del 40 aniversario del establecimiento de relaciones diplomáticas. En agosto de 2015 se llevó a cabo la visita del ministro de Cultura, Deportes y Turismo de Vietnam, Hoang Tuan Anh, en la que sostuvo encuentros con la entonces secretaria de Turismo, Claudia Ruiz Massieu. ${ }^{50}$ En la XII Cumbre de la Alianza del Pacífico, en junio de 2017 en Cali, Colombia, el secretario Luis Videgaray se reunió con el canciller de Nueva Zelanda, Gerry Brownlee. Ambos abordaron los temas de la integración económica transpacífica, los esquemas de cooperación en agricultura, ganadería y educación, la promoción del comercio y la inversión. ${ }^{51}$

\section{REFLEXIÓN FINAL}

La administración de los temas bilaterales y regionales de la agenda de México en el Pacífico durante 2012-2018 se realizó de manera normal en la primera etapa, la cual se intensificó con la propuesta del MiKTA. Empero, en la parte final del sexenio, la actividad diplomática se profundizó ante el impacto de la salida de Washington del TPP y las negociaciones del acuerdo comercial con Estados Unidos y Canadá.

Dentro de la agenda política, quizá un aspecto para subrayar fue la declaración del embajador de la República Popular Democrática de Corea, Kim Hyong Gil, como persona non grata, en septiembre de 2017 , en respuesta a las pruebas nucleares realizadas por Pyonyang, que representaban una violación al derecho internacional y a las resoluciones de la ONU, y por representar una amenaza para la paz en la región Asia Pacífico, en particular con aliados claves como Corea

${ }^{50} \mathrm{Ibid}$, p. 90.

${ }^{51}$ Secretaría de Relaciones Exteriores, SRE, Quinto Informe de Labores de la SRE, 2016-2017, op. cit., p. 96. 
del Sur y Japón, y del mundo en general. Esa condena al sexto ensayo nuclear se había expresado en el marco del мIкTA. En noviembre del mismo año, la SRE condenaría el lanzamiento de un misil balístico de Corea del Norte, además de solicitar su suspensión por efectuar actos que pudieran considerarse hostiles.

Sin embargo, el proceso de acercamiento del gobierno de Donald Trump con Kim Jong-un generó que México expresara su beneplácito para el proceso de diálogo y distensión en la península coreana. A finales de abril de 2018 expresó que se congratulaba por los resultados de la tercera cumbre intercoreana (la primera desde hacía once años) ocurrida en el lado de Corea del Sur del "área de seguridad conjunta" en Panmunjom.

La posición de México, un tanto comprometida ante el cambio de dirección en los asuntos de Corea del Norte, se sumó de nuevo a las expresiones de apoyo por el establecimiento del diálogo y la cooperación para alcanzar la desnuclearización de la península coreana. Por último, el gobierno mexicano consideró positiva la cumbre entre los líderes de Estados Unidos y Corea del Norte de 2018 en Singapur, como un medio para fortalecer el diálogo para lograr la pacificación en esa región del este asiático.

Más allá del episodio norcoreano, la política exterior mexicana para la región Asia Pacífico durante el sexenio de Enrique Peña Nieto mostró una labor congruente, dentro de los márgenes de acción posibles, para replantear su relación con Beijing, atender los temas de la agenda regional y ofrecer un mayor valor agregado con el MIKTA como foro de consulta, que intensificó los nexos de diálogo y cooperación con los países que lo integran. Asimismo, pudo responder a las necesidades de mantener un acercamiento constante con sus socios prioritarios. También está claro que ante el factor Trump, la diplomacia mexicana trató de abrir nuevos canales de comunicación con sus contrapartes asiáticas ante la renegociación del TLCAN y la incertidumbre para replantear el TPP como otro mecanismo de libre comercio. Los 
factores internos en México y el cambio abrupto de la agenda con Estados Unidos, determinaron que la posibilidad para cumplir la meta de perfilar al país como un actor con responsabilidad global sería menor, aun si pudo "gestionar" sus relaciones con el Pacífico asiático de manera asertiva para responder a los crecientes factores de incertidumbre observados durante el sexenio 2012-2018.

\section{REFERENCIAS}

Alba Ulloa, Jessica de, "Enrique Peña Nieto y el primer año de gobierno", Revista de Relaciones Internacionales de la UNAM, núm. 119 (mayo-agosto 2014).

"Concluye reunión de Enrique Peña con dignatarios", La Razón, México, $1^{\circ}$ de diciembre de 2012, https:/ / www.razon.com.mx/ concluye-reunion-de-enrique-pena-con-dignatarios/

Dávila Pérez, María del Consuelo y Rubén Cuéllar Laureano (coords.), La política exterior de México y sus nuevos desafíos, México, unAm/Plaza y Valdés, 2008.

González, Guadalupe y Olga Pellicer, Los retos internacionales de México. Urgencia de una mirada nueva, México, Editorial Siglo Xxi, 2011.

LARA, Carlos, "México y Japón deben ampliar más su relación comercial: Peña Nieto", El Sol de México, 10 de noviembre de 2017, https://www.elsoldemexico.com.mx/mexico/politica/mexi co-y-japon-deben-ampliar-mas-su-relacion-comercial-pena-nie to-310946.html

"Peña Nieto llega a Filipinas; participará en la APEC", El Financiero, 17 de noviembre de 2015, https://www.elfinanciero.com.mx/ mundo/pena-nieto-llega-a-filipinas-participara-en-la-apec

Rosenzweig Mendialdua, Francisco de, "México y su ingreso en el Acuerdo de Asociación Transpacífico", Revista de Derecho Económico Internacional, vol. 3, núm. 1, pp. 89-94.

"Ruiz Massieu participa en reunión de Alianza del Pacifico y ANSEA", Excélsior, 28 de septiembre de 2015, http:/ /www.excelsior.com. $\mathrm{mx} /$ nacional/2015/09/28/1048151 
Uscanga, Carlos, "La diplomacia de «último recurso» en la negociación del Tratado de Libre Comercio entre México y Corea del Sur, Revista Asia y América, vol. 11, núm. 1 (2011), pp. 165-181. VelázQuez Flores, Rafael, "El proyecto de política exterior de Felipe Calderón: ¿golpe de timón”? Revista de Relaciones Internacionales de la UNAM, núm. 108 (septiembre-diciembre de 2010).

\section{DOCUMENTOS OFICIALES, INFORMES Y LEYES}

Gobierno de la República, Plan Nacional de Desarrollo 2013-2018, México, 2013, https://www.gob.mx/presidencia/acciones-yprogramas/plan-nacional-de-desarrollo-2013-2018-78557

Presidencia de la República, "El Presidente Enrique Peña Nieto recibió a los Príncipes Akishino de Japón”, México, 2014.

Presidencia de la República, "El Presidente Enrique Peña Nieto se reunió con el Primer Ministro de la República de la India, Narendra Modi”, México, 2015,

Programa Sectorial de Relaciones Exteriores 2013-2018, Diario Oficial, Primera Sección, 13 de diciembre de 2013.

Secretaría de Economía, "El secretario de Economía realiza gira de trabajo a Japón" (comunicado de prensa), 10 de junio de 2018. Secretaría de Economía, "México participará en la XXV Reunión de Líderes Económicos del Foro de Cooperación Económica Asia-Pacífico (APEC)" (comunicado de prensa), 10 de noviembre de 2017.

Secretaría de Relaciones Exteriores, "El Canciller Videgaray se reúne con el Ministro de Asuntos Exteriores de Japón" (comunicado de prensa), 24 de mayo de 2018.

Secretaría de Relaciones Exteriores, Primer Informe de Labores de la SRE. 2012-2013, México, SRE, 2013, https://sre.gob.mx/organointerno-de-control-en-la-sre/75-transparencia-y-acceso-a-la-in formacion-publica-gubernamental/transparencia-y-acceso-ala-informacion-publica-gubernamental/1548-primer-informede-labores

Secretaría de Relaciones Exteriores, Segundo Informe de Labores de la SRE. 2013-2014, Gobierno de la República, México, SRE, 
2014,https://sre.gob.mx/images/stories/informe/2doinfor me.pdf

Secretaría de Relaciones Exteriores, Cuarto Informe de Labores de la SRE, 2015-2016, México, SRE, 2016, https://sre.gob.mx/sre-do cs/infolab/3erinfolab_a.pdf

Secretaría de Relaciones Exteriores, , Quinto Informe de Labores de la SRE, 2016-2017, México, SRE, 2017, https://sre.gob.mx/sredocs/infolab/3erinfolab_a.pdf 
